\title{
A quad band planar slotted microstrip patch antenna for wireless applications
}

\author{
Reshma Roy ${ }^{1}$, Apurva Singh ${ }^{2}$, Om Prakash Kumar ${ }^{3}$, Tanweer Ali ${ }^{4}$, Manohara Pai M. M. ${ }^{5}$ \\ ${ }^{1}$ Wipro Limited, India \\ ${ }^{2}$ KPIT Technologies, India \\ ${ }^{3,4}$ Department of Electronics \& Communication Engineering, Manipal Institute of Technology, \\ Manipal Academy of Higher Education, India \\ ${ }^{5}$ Department of Information and Communication Technology, Manipal Institute of Technology, \\ Manipal Academy of Higher Education, India
}

\section{Article Info}

Article history:

Received Dec 9, 2019

Revised Feb 5, 2020

Accepted Apr 14, 2020

\section{Keywords:}

Dual band

Quad band

Rectangular stub

Slot

\begin{abstract}
This research paper presents two different types of multiband patch antenna. The first design is a dual-band antenna and the second design is a quad-band antenna. Both the antennas have a compact size of $30 \times 30 \times$ $1.6 \mathrm{~mm}^{3}$, and is designed on FR4 substrate with loss tangent $(\delta)=0.02$, height $(\mathrm{h})=1.6 \mathrm{~mm}$, with dielectric constant of 4.4. The dual-band antenna operates at frequencies 3.9 and $5.71 \mathrm{GHz}$. These dual band operations are accomplished by utilizing L-shaped slot in the ground part and T-shaped slot in the radiating part of the patch antenna. The gain corresponding to the two frequency bands are 1.27 and $1.35 \mathrm{~dB}$, respectively. The quad band antenna operates at frequencies 3.6, 4.9, 7.4 and $8 \mathrm{GHz}$. The gain corresponding to these frequencies are $0.18,1.69,2.25$ and $3.99 \mathrm{~dB}$. For achieving quad band operation from the dual band antenna the back plane L-shaped slot is modified by cutting a rectangular strip in the middle, hence dividing it into two different slots. The front plane is also modified by introducing two rectangular strips to the T-shaped patch. The proposed antenna shows multiband and has the advantage of simple structure compact size and good impedance matching. All the simulations of the proposed design are carried out in HFSS v.13.0.
\end{abstract}

This is an open access article under the CC BY-SA license.

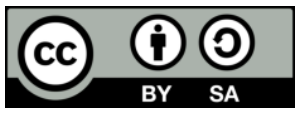

\section{Corresponding Author:}

Tanweer Ali,

Department of Electronics \& Communication Engineering,

Manipal Institute of Technology,

Manipal Academy of Higher Education, Manipal, India.

Email: tanweer.ali@manipal.edu

\section{INTRODUCTION}

Due to the competitive advancements in the area of wireless communications in recent years, there is a necessity for efficient designing of the antenna, as it plays a significant role in the functioning of the wireless system [1-7]. The discovery of multiband nature of antennas was an important revolution in this field. Different types of antenna designed to cover the wireless applications are monopole [8-11], dipole [12], patch antenna [13-15] etc. In order to fulfill the criteria of good wireless quality and larger implantation coverage on one device, multiband antennas prove to be very beneficial as each part covers the best operation of a particular band.

Various types of microstrip fed antennas are proposed due to its simple structure and its ability to easily integrate with RF circuits. In [16] a quad-band antenna of size $30 \times 30 \times 1.6 \mathrm{~mm}^{3}$ at operating 
frequencies 1.6, 2.5, 5.8 and $9.5 \mathrm{GHz}$ is proposed. The antenna proposed in [17] has a size of $25 \times 30 \times 0.8 \mathrm{~mm}^{3}$ and operates at dual-band frequencies 2.4 and $5.5 \mathrm{GHz}$. In [18], two antennas are proposed where the second antenna is the optimized version of the first antenna. First one is a dual band antenna with operating frequencies of 1.5 and $3.5 \mathrm{GHz}$. The second being a triple band antenna operates at frequencies $1.5,3.5$ and $5.5 \mathrm{GHz}$. However, the size of both antenna are $180 \times 80 \times 1.6 \mathrm{~mm}^{3}$ which is large. The work discussed in [19] depicts an antenna of size $35.5 \times 26 \times 6 \mathrm{~mm}^{3}$ at operating frequencies 3.6, 5 and $5.6 \mathrm{GHz}$ (triple band) thus, covering WiMAX and WLAN applications. Similarly, dual band antennas are proposed in [20,21] of size $17 \times 20 \times 1.6 \mathrm{~mm}^{3}$ and $40 \times 30 \times 0.8 \mathrm{~mm}^{3}$ operating at resonant frequencies of 1.72 and $5.3 \mathrm{GHz}$ and 2.4 and $5.6 \mathrm{GHz}$. In [22] a triple band antenna is proposed operating at frequencies $2.0,2.45$ and $3.5 \mathrm{GHz}$ of size $200 \times 200 \times 0.8 \mathrm{~mm}^{3}$ which is relatively larger and also covers larger space on the PCB material. A dual band antenna operating at 0.4 and $2.4 \mathrm{GHz}$ is proposed in [23]. The quad band antenna that is proposed in [24] has a size of $25 \times 20 \mathrm{~mm}^{2}$ with an operating frequencies of $2.4,3.5,5.2$ and $5.8 \mathrm{GHz}$. Good impedance matching $\left(\mathrm{S}_{11}<-10 \mathrm{~dB}\right)$ is achieved with coverage of WiMAX/WLAN ranges. In [25], a triple band antenna of size $18 \times 19 \mathrm{~mm}^{2}$ operates at frequencies $2.4,3.5$ and $5.5 \mathrm{GHz}$ is proposed. The above mentioned antenna shows multiband operation however they suffer from the disadvantage of complex structure [16-25], large size such as [18, 19, 21, 22], less number of operating bands [13-18, 25]. The antenna proposed in this paper removes the aforementioned disadvantages and hence is a competitive candidate for diverse wireless applications.

Multiband antennas not only cover various applications but also display features like size, cost and high data rate. In this research paper two types of patch antennas are presented. The first one is a dual-band antenna having a compact size of $30 \times 30 \times 1.6 \mathrm{~mm}^{3}$ and operates at frequencies 3.9 and $5.71 \mathrm{GHz}$. The gain corresponding to the two frequency bands are 1.27 and $1.35 \mathrm{~dB}$ respectively. The second one is a quad-band antenna having the same compact size as of dual band and operates at frequencies 3.6, 4.9, 7.4 and $8 \mathrm{GHz}$. The gain corresponding to these frequencies are $0.18,1.69,2.25$ and $3.99 \mathrm{~dB}$. The dual-band antenna has an L-shaped slot in the ground part and a T-shaped radiating stub in the front part, in order to achieve the required frequency bands. In the quad-band antenna which is evolved from dual band antenna, has a rectangular and L-shaped slots in the back plane and a modified T-shaped radiating stub in the front plane.

\section{DUAL BAND ANTENNA DESIGN}

\subsection{Design equation}

The width and the length of the microstrip patch antenna are evaluated as given in (1)-(6) [26].

$$
\begin{aligned}
& \text { Width }=\frac{c}{2 f_{0} \sqrt{\frac{\varepsilon_{r}+1}{2}}} \\
& \text { Length }=\frac{c}{2 f_{0} \sqrt{\varepsilon_{e f f}}}-0.824 h\left(\frac{\left(\varepsilon_{e f f}+0.3\right)\left(\frac{w i d t h}{h}+0.264\right)}{\left(\varepsilon_{e f f}-0.258\right)\left(\frac{\text { width }}{h}+0.8\right)}\right) \\
& \varepsilon_{\text {eff }}=\frac{\varepsilon_{r}+1}{2}+\frac{\varepsilon_{r}-1}{2}\left(\frac{1}{\sqrt{1+12 \frac{h}{\text { width }}}}\right)
\end{aligned}
$$

The length and width of the strip line are evaluated as (4)-(6) [21],

$$
\begin{aligned}
& \text { strip line length }=\frac{\lambda_{g}}{4} \\
& \frac{\text { Strip line width }}{h}=\frac{8 \exp (A)}{\exp (2 A)-2}
\end{aligned}
$$

Where, $A=\frac{Z_{L}}{60}\left(\frac{\varepsilon_{r}+1}{2}\right)^{1 / 2}+\left(\frac{\varepsilon_{r}-1}{\varepsilon_{r}+1}\right)\left(0.23+\frac{0.11}{\varepsilon_{r}}\right)$

\subsection{Design evolution}

Firstly, a dual band antenna is designed which is again optimized in order to achieve a quad band. Figure 1(a) illustrates the evolution stages of proposed dual band antenna. Firstly, a $\mathrm{T}$ shaped patch is designed on the front plane with full ground plane on the back side (i.e. "R1") as presented in Figure 1(a). This antenna operates at 3.8 and $7.5 \mathrm{GHz}$ with gains- 0.38 and $2.73 \mathrm{~dB}$ respectively as depicted in Figure 1 (b) 
and Figure 1(c). The reflection coefficients $\left(S_{11}\right)$ are-14.6 and-9.98dB at 3.8 and $7.5 \mathrm{GHz}$ respectively. Hence one lower frequency band is achieved at $3.8 \mathrm{GHz}$ (covering WiMAX range) with good impedance matching $\left(\mathrm{S}_{11}<-10 \mathrm{~dB}\right)$ but gain is negative. Second band is formed towards higher frequency range (covering X-band) with positive gain but have less impedance matching. For better impedance matching, a rectangular slot is made on the back plane as presented in configuration "R2" of Figure 1(a). It operates at 3.8 and $7.6 \mathrm{GHz}$ with gains- 0.14 and $2.09 \mathrm{~dB}$ as depicted in Figure 1(b) and Figure 1(c). The values of $\mathrm{S}_{11}$ are-14.28 at 3.8 and $-8.6 \mathrm{~dB}$ at $7.6 \mathrm{GHz}$.

It is observed that the operating frequency bands remain same for both the configurations i.e. "R1" and "R2", but at $7.6 \mathrm{GHz}$ impedance matching improves. In order to get desired frequency bands with positive gains and good impedance matching, the rectangular slot is modified resulting in an inverted L-shaped slot on the back plane, and the front plane is kept same as presented in configuration "R3" of Figure 1(a). With this modification the antenna operates at 3.9 and $5.7 \mathrm{GHz}$ with gains 1.27 and $1.35 \mathrm{~dB}$ respectively, as presented in Figure 1(b) and Figure 1(c). $\mathrm{S}_{11}$ values are-21.55 dB at $3.9 \mathrm{GHz}$ and-14.73dB at $5.7 \mathrm{GHz}$. So the higher frequency band shifts to a lower one thus, covering WLAN range (i.e. the band with resonating frequency at $7.6 \mathrm{GHz}$ shifts to $5.7 \mathrm{GHz}$ ). Gains are also positive for both narrow bands and the reflection coefficients are also <-10dB for the configuration "R3". Hence, "R3" is the proposed dual band antenna. The $\mathrm{S}_{11}$ and gain plots of all the evolution stages (till "R3") are detailed in Figure 1.

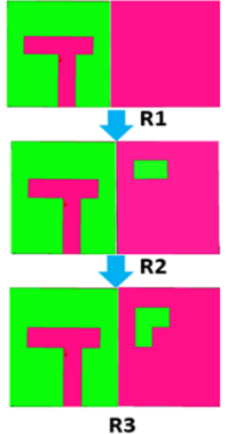

(a)

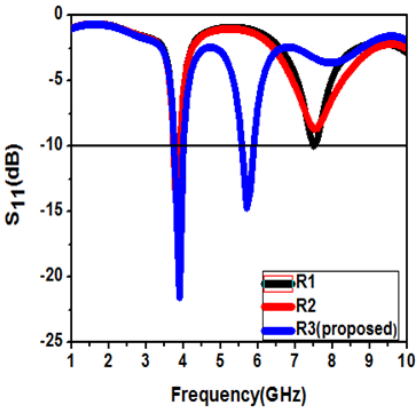

(b)

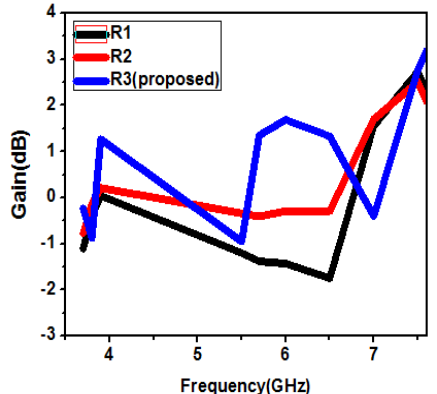

(c)

Figure 1. Proposed dual band antenna, (a) Evolution stage, (b) $\mathrm{S}_{11}$ results, (c) Variation of gain with frequency for different configurations

The overall proposed design of dual band antenna is outlined in Figure 2. The proposed configuration i.e. "R3" consists of T-shaped stub like radiating patch and inverted L-shaped slot on ground plane. The antenna is fed using rectangular microstrip feedline to achieve an impedance matching of $50 \mathrm{ohm}$.

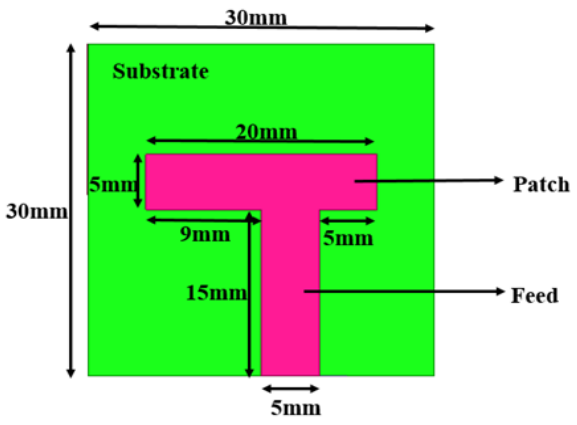

(a)

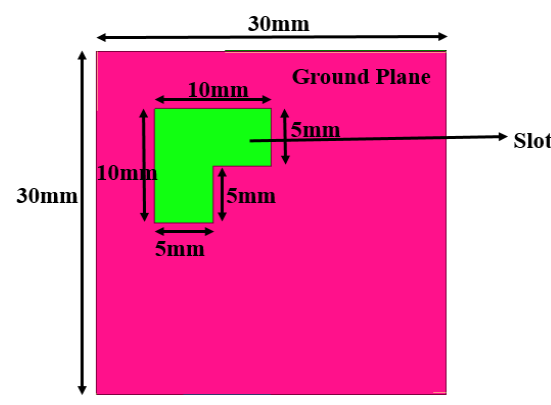

(b)

Figure 2. Proposed "R3” configuration, (a) Front view, (b) Back view

The current distribution of dual band antenna is presented in Figure 3. At $3.9 \mathrm{GHz}$, the horizontal part of T-shaped stub is more active as dense red color current is more in that area. Similarly, at $5.7 \mathrm{GHz}$ the feed of the stub is more active with scattered distribution of current at the ground part. These current distributions clearly explains the importance of etching slots and stubs for the required dual band resonanace. 


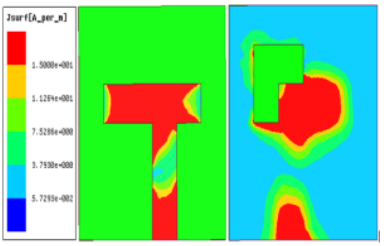

(a)

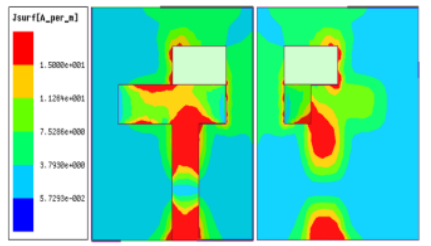

(b)

Figure 3. Current distribution at (a) 3.9 , (b) $5.7 \mathrm{GHz}$

\section{QUAD BAND ANTENNA DESIGN}

\subsection{Design evolution}

The evolution stages for quad band antenna from dual band antenna is presented in Figure 4(a). The ground part of configuration "R3" (i.e. proposed dual band antenna) is kept same whereas on the front plane the patch is modified by adding rectangular strips in order to achieve more number of frequency bands. Because of this modification the total current length path of the configuration "R4" changes thus making it to operate at 3.7 and $5.7 \mathrm{GHz}$ with gains 1.1 and $0.91 \mathrm{~dB}$ respectively, as outlined in Figure 4(b) and Figure 4(c). The reflection coefficients $\left(\mathrm{S}_{11}\right)$ are-13.38 and-12.17 dB at 3.7 and $5.7 \mathrm{GHz}$. The ground part of configuration "R4" is kept on modifying until quad bands are achieved at the desired frequencies. Now the front plane is kept same and on back side the L-shaped slot is modified by adding a rectangular strip in between leading to formation of two slots as outlined in configuration "R5" of Figure 4(a). It operates at 4.8, 7.4 and $8 \mathrm{GHz}$ with gains $1.65,2.25$ and $3.99 \mathrm{~dB}$, and $\mathrm{S}_{11}$ values-16.94,-21.38 and-13.67 dB respectively, as outlined in Figure 4(b) and Figure 4(c). Hence, three bands are achieved with all positive gains and good impedance matching. In order to incorporate more band a small rectangular slot is cut out from lower slot at the ground plane (now this slot becomes inverted L-shaped) and the front plane is kept same leading to the configuration "R6" as depicted in Figure 4(a). The incorporation of this slot further deviates the patch current length path which in turn increase the total current flow area thereby making the configuration "R6" to exhibit additional operating band at $3.6 \mathrm{GHz}$ (WiMAX).

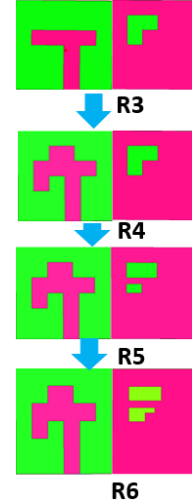

(a)

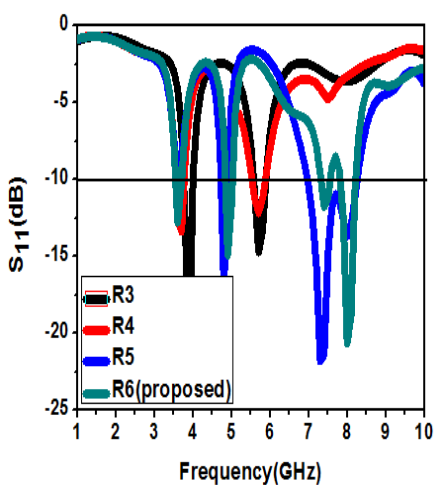

(b)

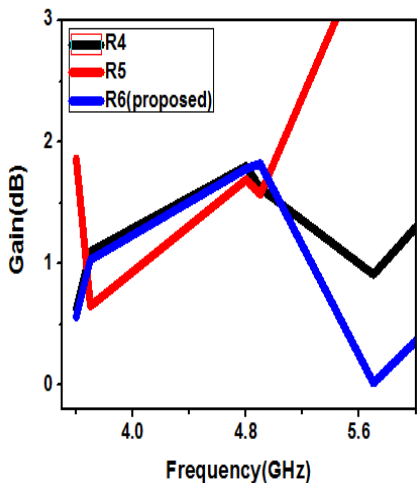

(c)

Figure 4. (a) Evolution stage of quad band antenna, (b) $S_{11}$ results, (c) Variation of gain with frequency

From Figure 4(b) and Figure 4(c), it can be seen that now configuration "R6" operates at 3.6, 4.9, 7.4 and $8 \mathrm{GHz}$ with gains $0.56,1.82,1.98$ and $4.02 \mathrm{~dB}$ having $\mathrm{S}_{11}-12.79,-14.92,-11.77$ and-20.66 $\mathrm{dB}$, respectively. "R6" is the quad band antenna that is proposed with four operating bands at the desired frequencies (covering WLAN/WiMAX) having acceptable gains and $S_{11}$ values less than-10dB resulting in good impedance matching. Thus, between dual band and quad band antennas discussed above the latter being a quad band antenna (R6) is better and hence the final proposed structure.

The overall proposed design of the quad band antenna is outlined in Figure 5. The antenna consists of T-shaped stub like radiating patch with rectangular strips attached to it and two slots on the ground plane, one being a rectangular slot and other being an inverted L-shaped slot. The antenna is feed using rectangular microstrip feedline to achieve an impedance matching of $50 \Omega$ (as already discussed in dual band antenna). 


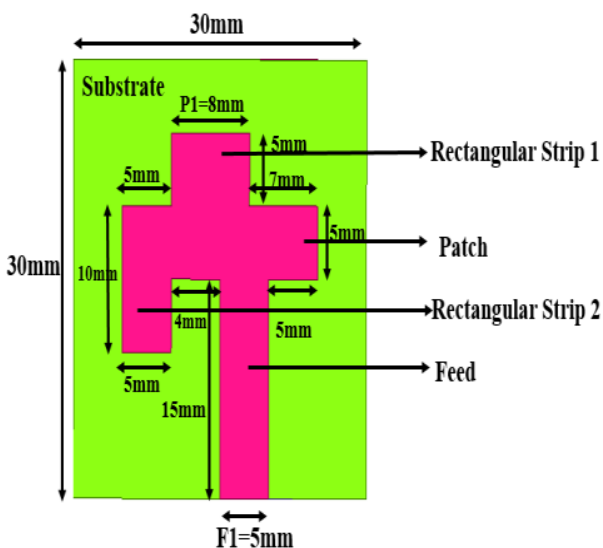

(a)

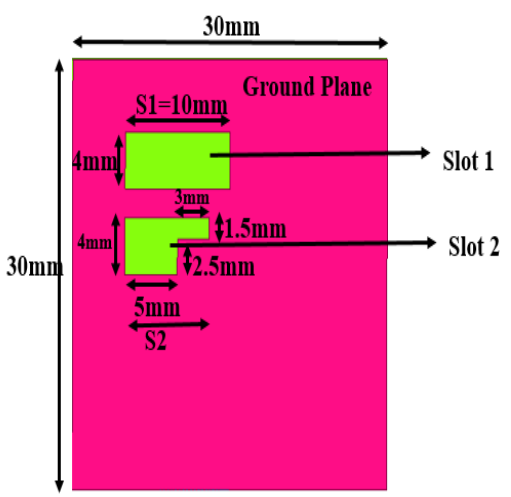

(b)

Figure 5. Proposed "R6" configuration, (a) Front view, (b) Back view

The current distribution of quad band antenna at the operating frequencies 3.6, 4.9, 7.4 and $8 \mathrm{GHz}$, are shown in Figure 6. It is seen that for different operating bands corresponding part of the antenna becomes active.

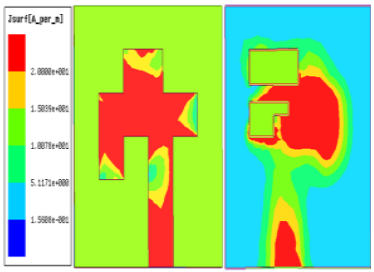

(a)

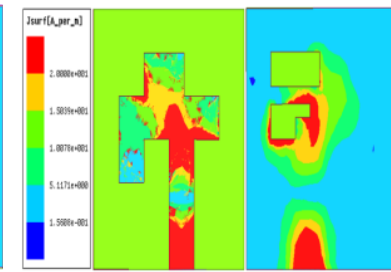

(b)

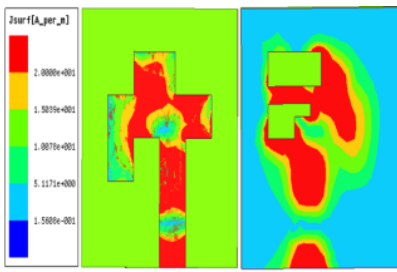

(c)

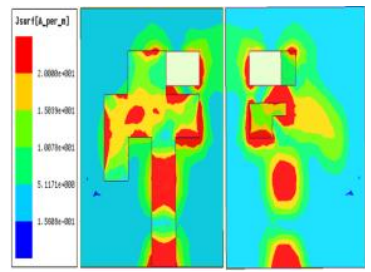

(d)

Figure 6. Current distribution at (a) 3.9, (b) 4.9, (c) 7.4, (d) $8 \mathrm{GHz}$

\section{RESULTS AND DISCUSSIONS}

\subsection{Results of dual band antenna (i.e. proposed configuration "R3")}

The proposed structure of dual band antenna has a total dimension of $30 \times 30 \times 1.6 \mathrm{~mm}^{3}$ at lower resonance of $3.9 \mathrm{GHz}$. The proposed dual band antenna operates at two bands with $\mathrm{S}_{11}<-10 \mathrm{~dB}$ bandwidth of about $300 \mathrm{MHz}(3.7-4.0 \mathrm{GHz})$ and $500 \mathrm{MHz}(5.4-5.9 \mathrm{GHz})$, respectively as presented in Figure 7(a). Both resonating bands fulfils the criteria of good impedance matching $\left(S_{11}<-10 \mathrm{~dB}\right)$ and acceptable gain. The proposed dual band antenna can work for middle WiMAX (3.9 GHz) and WLAN (5.7 GHz) applications. The input impedance graph of the dual band antenna is presented in Figure 7(b). The dual band antenna has an input impedance of (58-j4) $\Omega$ at $3.9 \mathrm{GHz}$, and (72-j0.6) $\Omega$ at $5.7 \mathrm{GHz}$, respectively. [Note Y1 represents input impedance]. The Table 1 shows the detailed results of the designed dual band antenna.

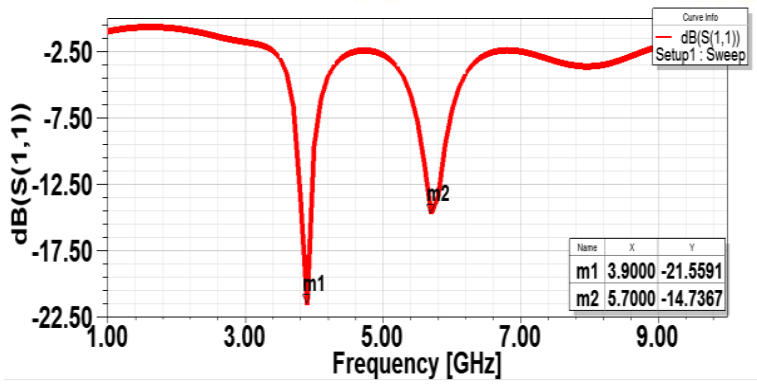

(a)

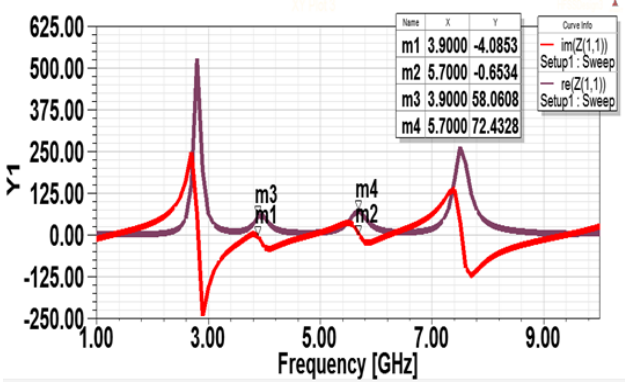

(b)

Figure 7. (a) $\mathrm{S}_{11}$ versus frequency, (b) Impedance vs frequency of dual band antenna 
Table 1. Summarized results of dual band antenna

\begin{tabular}{cccccc}
\hline \multicolumn{5}{c}{ Dual band antenna (proposed configuration "R3") } \\
\hline $\begin{array}{c}\text { Frequency } \\
(\mathrm{GHz})\end{array}$ & $\begin{array}{c}\mathrm{S}_{11} \\
(\mathrm{~dB})\end{array}$ & $\begin{array}{c}-10 \mathrm{~dB} \text { impedance } \\
\text { Bandwidth }(\mathrm{GHz})\end{array}$ & \% Bandwidth & $\begin{array}{c}\text { Gain } \\
(\mathrm{dB})\end{array}$ & Applications \\
\hline 3.9 & -21.55 & $3.7-4.0$ & 2.5 & 1.27 & Middle WiMAX \\
5.7 & -14.73 & $5.4-5.9$ & 4.16 & 1.35 & WLAN \\
\hline
\end{tabular}

The radiation pattern for the two operating frequencies are depicted in the Figure 8 . The antenna has directional radiation pattern in both the plane (i.e. $\varphi=0^{\circ}(E-$ pane $)$ and $\varphi=90^{\circ}(H-$ Plane $)$.

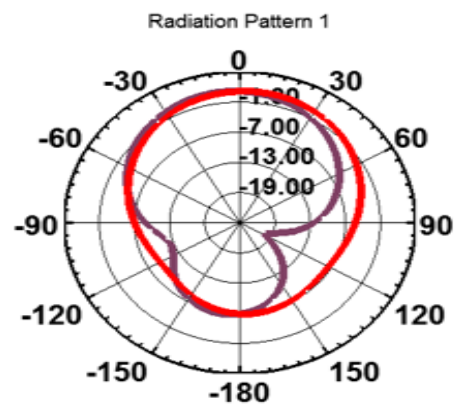

(a)

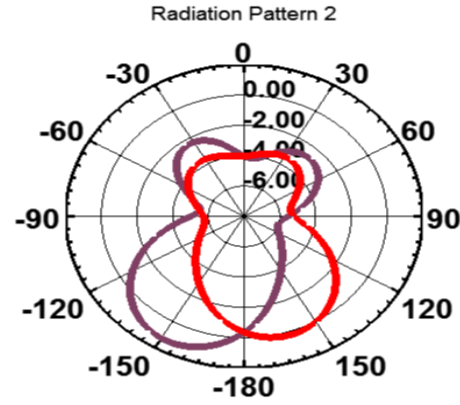

(b)

Figure 8. Radiation patterns at (a) 3.9 , (b) $5.7 \mathrm{GHz}$

[Note: $\left(\varphi=0^{\circ}(E-\right.$ pane $)-$ blue color and $\varphi=90^{\circ}(H-$ Plane $)-$ red color ]

\subsection{Results of quad band antenna (i.e. proposed quad band configuration "R6")}

In order to achieve the quad band antenna, the dual band antenna is modified. It also has a total dimension of $30 \times 30 \times 1.6 \mathrm{~mm}^{3}$ at lower resonant frequency of $3.6 \mathrm{GHz}$. The proposed quad band configuration "R6" operates at four bands with $\mathrm{S}_{11}<-10 \mathrm{~dB}$ bandwidth of about $200 \mathrm{MHz}(3.5-3.7 \mathrm{GHz})$ centered at $3.6 \mathrm{GHz}, 200 \mathrm{MHz}(4.8-5.0 \mathrm{GHz})$ centered at $4.9 \mathrm{GHz}, 200 \mathrm{MHz}(7.3-7.5 \mathrm{GHz})$ centered at 7.4 GHz, and $400 \mathrm{MHz}(7.8-8.2 \mathrm{GHz})$ centered at $8 \mathrm{GHz}$, respectively, as presented in Figure 9(a). All the four operating bands fulfils the criteria of good impedance matching $\left(\mathrm{S}_{11}<-10 \mathrm{~dB}\right)$ and positive gains. The proposed quad band antenna can work for middle WiMAX (3.6 GHz), WLAN (5 GHz) and X-band (7.4 and $8 \mathrm{GHz}$ ) applications. The input impedance graph of the quad band antenna is presented in Figure 9(b). The quad band antenna has an input impedance of $(51+\mathrm{j} 23.8) \Omega$ at $3.6 \mathrm{GHz},(38+\mathrm{j} 11) \Omega$ at 4.9 GHz, (29-j0.2) $\Omega$ at $7.4 \mathrm{GHz}$ and $(44+\mathrm{j} 7.1) \Omega$ at $8 \mathrm{GHz}$ respectively. [Note Y1 represents input impedance]. The detailed summarized results of the quad band are given in Table 2.

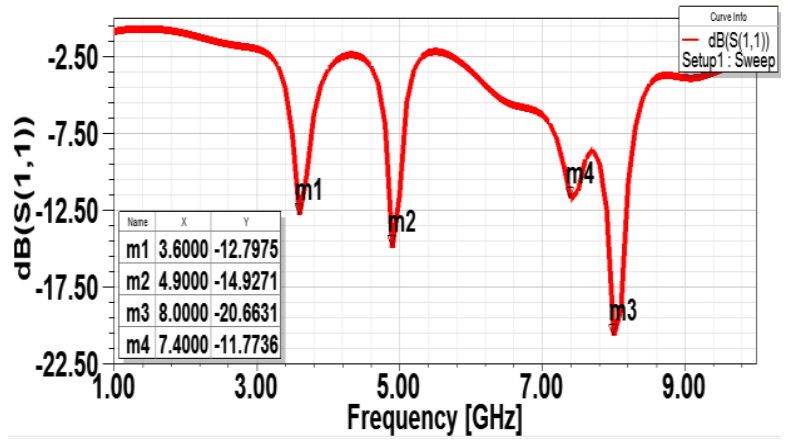

(a)

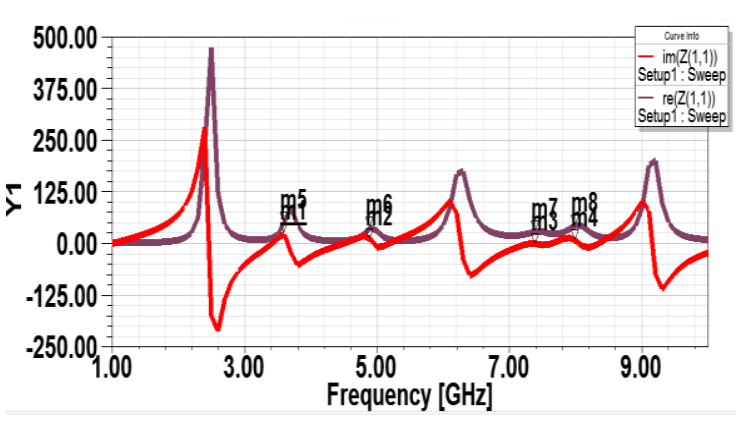

(b)

Figure 9. (a) $S_{11}$ versus frequency, (b) Impedance vs frequency of the proposed quad band antenna 
Table 2. Summarized results of quad band antenna

\begin{tabular}{cccccc}
\hline \multicolumn{7}{c}{ Quad band antenna (prposed configuration "R6") } \\
\hline $\begin{array}{c}\text { Frequency } \\
(\mathrm{GHz})\end{array}$ & $\mathrm{S}_{11}(\mathrm{~dB})$ & $\begin{array}{c}\text {-10 dB impedance } \\
\text { Bandwidth }(\mathrm{GHz})\end{array}$ & \% Bandwidth & $\begin{array}{c}\text { Gain } \\
(\mathrm{dB})\end{array}$ & Applications \\
\hline 3.6 & -12.79 & $3.5-3.7$ & 1.67 & 0.56 & Middle WiMAX \\
4.9 & -14.92 & $4.8-5.0$ & 1.67 & 1.82 & WLAN \\
7.4 & -11.77 & $7.3-7.5$ & 1.67 & 1.98 & WLAN \\
8.0 & -20.66 & $7.8-8.2$ & 3.33 & 4.02 & X-band \\
\hline
\end{tabular}

The radiation pattern at the four operating frequencies 3.6, 4.9, 7.4 and $8 \mathrm{GHz}$ are presented in Figure 10. Here, also we can see that like dual band antenna, the quad band antenna has stable and directional pattern both in $\varphi=0^{\circ}(E-$ pane $)$ and $\varphi=90^{\circ}(H-$ Plane $)$.

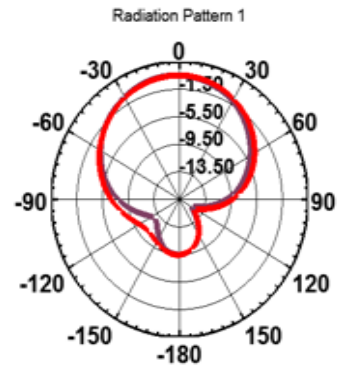

(a)

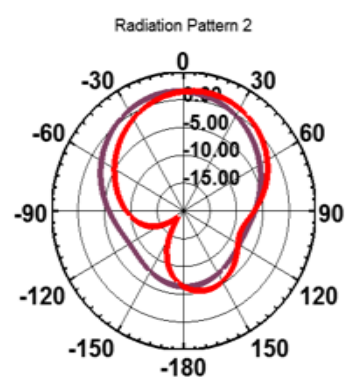

(b)

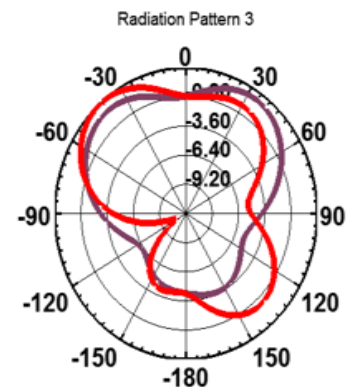

(c)

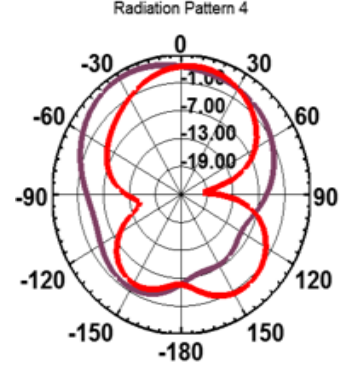

(d)

Figure 10. Radiation patterns of the quad band antenna at (a) 3.6, (b) 4.9, (c) 7.4, (d) $8 \mathrm{GHz}$

[Note:- $\left(\varphi=0^{\circ}(E-\right.$ pane $)-$ blue color and $\varphi=90^{\circ}(H-$ Plane $)-$ red color ]

A comparison between the proposed configurations with similar type existing in the literature is performed and presented in Table 3. The proposed antenna as can be seen from table has advantageous over its counterparts.

Table 3. Comparative analysis of the proposed dual and quad band antenna with similar type in the literature

\begin{tabular}{|c|c|c|c|c|c|}
\hline Ref. & Size $\left(\mathrm{mm}^{2}\right)$ & $\begin{array}{l}\text { No. of } \\
\text { bands }\end{array}$ & $\begin{array}{c}\text { Operating } \\
\text { Frequencies }(\mathrm{GHz})\end{array}$ & $\begin{array}{l}\text { Operating Bandwidth } \\
(\mathrm{GHz})\end{array}$ & Applications \\
\hline$[16]$ & $30 \times 30$ & 4 & $1.6 / 2.5 / 5.8 / 9.5$ & $(1.7-1.9) /(2.7-3) /(5.6-5.9) /(9.2-10.1)$ & GPS/WiMAX/WLAN/X-band \\
\hline [17] & $25 \times 30$ & 2 & $2.4 / 5.5$ & $(1.87-2.99) /(5.1-5.88)$ & WLAN/WiMAX \\
\hline \multirow[t]{2}{*}{ [18] } & a) $180 \times 80$ & 2 & $1.5 / 3.5$ & $(1.43-1.62) /(3.36-3.64)$ & GPS/WiMAX \\
\hline & b) $180 \times 80$ & 3 & $1.5 / 3.5 / 5.5$ & $(1.35-1.56) /(3.33-3.54) /(5.34-5.68)$ & GPS/WiMAX \\
\hline [19] & $35.5 \times 26$ & 3 & $3.6 / 5 / 5.6$ & $(3.5-3.75) /(4.85-5.2) /(5.5-5.7)$ & WiMAX/WLAN \\
\hline [20] & $17 \times 20$ & 2 & $1.72 / 5.30$ & $(1.6-1.85) /(4.95-5.8)$ & GPS/WLAN \\
\hline [21] & $40 \times 30$ & 2 & $2.4 / 5.6$ & $(2.39-2.51) /(5-6.1)$ & WLAN/WiMAX \\
\hline [22] & $200 \times 200$ & 3 & $2 / 2.45 / 3.5$ & $(1.93-2.15) /(2.35-2.58) /(3.27-3.72)$ & WLAN/Bluetooth/WiMAX \\
\hline [23] & $16.5 \times 16.5$ & 2 & $0.402 / 2.4$ & $(0.43-0.49) /(2.47-2.58)$ & WLAN \\
\hline [24] & $25 \times 20$ & 4 & $2.4 / 3.5 / 5.2 / 5.8$ & $(2.07-2.77) /(3.3-3.8) /(5.15-5.35) /(5.7-5.89)$ & WLAN/WiMAX \\
\hline [25] & $18 \times 19$ & 3 & $2.4 / 3.5 / 5.5$ & $(2.40-2.51) /(3.35-3.94) /(5.02-6.63)$ & WLAN/WiMAX \\
\hline \multirow{2}{*}{ Prop. } & a) $30 \times 30$ & 2 & $3.9 / 5.7$ & $(3.7-4) /(5.4-5.9)$ & WiMAX/WLAN \\
\hline & b) $30 \times 30$ & 4 & $3.6 / 4.9 / 7.4 / 8$ & $(3.5-3.7) /(4.8-5) /(7.3-7.5) /(7.8-8.2)$ & WiMAX/WLAN/X-band \\
\hline
\end{tabular}

\section{CONCLUSION}

In this paper, two antennas have been designed and analyzed. First antenna operates at dual band and the second operates at quad band. The dual band antenna exhibits operating frequency at 3.9 (WiMAX) and $5.7 \mathrm{GHz}$ (WLAN), with fractional bandwidth of $2.5 \%$ and $4.16 \%$ respectively. The quad band antenna has operating frequencies at 3.6 (WiMAX), 4.9 (WLAN), 7.4 and $8 \mathrm{GHz}$ (X-band) with fractional bandwidth of $1.67 \%, 1.67 \%, 1.67 \%$ and $3.33 \%$, respectively. Both the antenna exhibits good impedance matching and have stable radiation patterns. These antennas have been designed in order to cover the WiMAX, WLAN and $\mathrm{X}$-band applications. Changes in slots dimensions affects the impedance matching of the antennas which has been depicted in the parametric analysis. The proposed antenna is compact in nature, has simple design 
configuration, acceptable gain and bandwidth, thus, serves as a competitive candidate for the aforementioned wireless applications.

\section{REFERENCES}

[1] T. Ali, et al., "A miniaturized slotted ground structure UWB antenna for multiband applications," Microwave and Optical Technology Letters, vol. 60, no. 8, pp. 2060-2068, Aug 2018.

[2] W. Balani, et al., "Design Techniques of Super-Wideband Antenna-Existing and Future Prospective," IEEE Access, vol. 7, pp. 141241-141257, 2019.

[3] A. Jaiswal, et al., "A novel circular slotted microstrip-fed patch antenna with three triangle shape defected ground structure for multiband applications," Advanced Electromagnetics, vol. 7, no. 3, pp. 56-63, 2018.

[4] T. Ali, et al., "A miniaturized multiband reconfigurable fractal slot antenna for GPS/GNSS/Bluetooth/WiMAX/Xband applications," AEU-International Journal of Electronics and Communications, vol. 94, pp. 234-243, 2018.

[5] W. L. Cheor, et al., "Study of multiple antennas with defected ground slot for low-band LTE application," Bulletin of Electrical Engineering and Informatics, vol. 8, no. 1, pp. 83-89, Mar 2019.

[6] Fathima, N., et al.,"A miniaturized slotted ground fractal Koch multiband antenna for wireless applications," in 2017 2nd IEEE International Conference on Recent Trends in Electronics, Information \& Communication Technology (RTEICT), pp. 251-255, 2017.

[7] Ali, T., et al., "A miniaturized slotted multiband antenna for wireless applications," Journal of Computational Electronics, vol. 17, no. 3, pp.1056-1070, 2018.

[8] R. Nibir, et al., "Multiband antenna using stacked series array for Ka-Band application," Bulletin of Electrical Engineering and Informatics, vol. 8, no. 3, pp. 994-1003, Sep 2019.

[9] M. Karthikeyan, et al., "Compact multiband CPW fed monopole antenna with square ring and T-shaped strips," Microwave and Optical Technology Letters, vol. 62, no. 2, pp. 926-932, Feb 2020.

[10] Mohammad, S. A., et al., "A miniaturized truncated ground plane concentric ring shaped UWB antenna for wireless applications," in 2017 2nd IEEE International Conference on Recent Trends in Electronics, Information \& Communication Technology (RTEICT), pp. 116-120, 2017.

[11] Ali, T., et al., "A Compact Bandwidth Enhanced Antenna Loaded with SRR For WLAN/WiMAX/Satellite Applications," Advanced Electromagnetics, vol. 7, no. 4, pp.78-84, 2018.

[12] D. Samantaray, et al., "Modified Fractal-shaped Slotted Patch Antenna with Dipole-shaped Slotted Ground Plane with Enhanced Gain for X-band Applications," in 2018 IEEE Indian Conference on Antennas and Propogation (InCAP), pp. 1-4, 2018.

[13] M. S. Islam, et al., "Microstrip patch antenna with defected ground structure for biomedical application," Bulletin of Electrical Engineering and Informatics, vol. 8, no. 2, pp. 586-595, Jun 2019.

[14] P. A. Ambresh, et al., "Novel Multi-Slotted Stripline Fed Patch Antenna with Wideband Characteristics for Wireless Applications," IUP Journal of Telecommunications, vol. 11, no. 1, pp. 7-14, 2019.

[15] Prasad, K. D., et al., "A compact slotted multiband antenna for L-band and WLAN applications," in 2017 2nd IEEE International Conference on Recent Trends in Electronics, Information \& Communication Technology (RTEICT), pp. 820-823, 2018.

[16] T. Ali, "A multiband reconfigurable slot antenna for wireless applications," AEU-International Journal of Electronics and Communications, vol. 84, pp. 273-280, 2018.

[17] S. Chen, et al., "Compact wideband and dual-band antenna for TD-LTE and WLAN applications," Electronics letters, vol. 50, no. 16, pp. 1111-1112, 2014.

[18] S. Chen, et al., "Dual-band/tri-band/broadband CPW-fed stepped-impedance slot dipole antennas," IEEE transactions on antennas and propagation, vol. 62, no. 1, pp. 485-490, Jan 2014.

[19] W. C. Mok, et al., "Single-layer single-patch dual-band and triple-band patch antennas," IEEE transactions on antennas and propagation, vol. 61, no. 8, pp. 4341-4344, Aug 2013.

[20] M. N. Moghadasi, et al., "A small dual-band CPW-fed monopole antenna for GSM and WLAN applications," IEEE antennas and wireless propagation letters, vol. 12, pp. 508-511, 2013.

[21] X. L. Sun, et al., "Dual-band antenna with compact radiator for 2.4/5.2/5.8 GHz WLAN applications," IEEE transactions on Antennas and Propagation, vol. 60, no. 12, pp. 5924-5931, Dec 2012.

[22] J. Kim, "Compact multiband microstrip antenna using inverted-L-and T-shaped parasitic elements," IEEE Antennas and Wireless Propagation Letters, vol. 12, pp. 1299-1302, 2013.

[23] C. Liu, et al., "Compact dual-band antenna for implantable devices," IEEE Antennas and Wireless Propagation Letters, vol. 11, pp. 1508-1511, 2012.

[24] X. Sun, et al., "A compact quadband CPW-fed slot antenna for M-WiMAX/WLAN applications," IEEE Antennas and Wireless Propagation Letters, vol. 11, pp. 395-398, 2012.

[25] W. Hu, et al., "Compact multiresonator-loaded planar antenna for multiband operation," IEEE Transactions on Antennas and Propagation, vol. 61, no. 5, pp. 2838-2841, May 2013.

[26] C. A. Balanis, “Antenna theory: analysis and design,” John wiley \& sons, 2016. 


\section{BIOGRAPHIES OF AUTHORS}

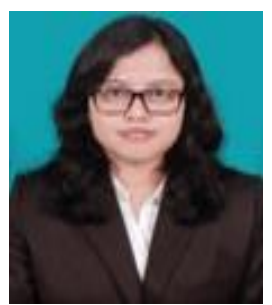

Reshma Roy is working as a Project Engineer at Wipro Research and Development Wing at Bangalore India. She has authored several research paper in many peer-reviewed high impact factor journals. Her research area intrests are metamaterial antennas, UWB antennas, multiband antennas, wireless power transfer, near field communications etc.

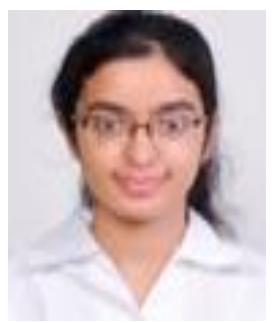

Apurva Singh is working as a Graduate Engineer Trainee at KPIT Technologies Research and Development Wing at Bangalore India. She has authored numerous research paper in many peerreviewed high impact factor journals. Her research area intrests are wideband antennas, UWB and SWB antennas, multiband antennas, Dielectric resonator antennas for 5G communications etc.

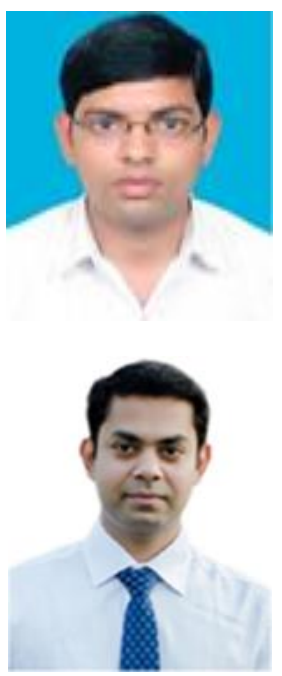

Om Prakash Kumar is an Assistant Professor in the Dept. of Electronics \& Communication Engineering at Manipal Institute of Technology, Manipal Academy of Higher Education, Manipal. He has authored more than 20 research article in high impact factor SCI journals. His research field includes UWB Antennas, Multiband antennas and metamaterial antennas.

Tanweer Ali is working as Assistant Professor in the Department of Electronics \& Communication Engineering at Manipal Instituteof Technology, Manipal Academy of Higher Education, Manipal. He is an active researcher in the field of microstrip antennas, wireless communication and microwave Imaging. He has published more than 65 papers in reputed peer reviewed international journal and conferences. He is a senior member IEEE (SMIEEE), and Associate Member of IETE India. He is on the board of reviewers of journals like the IEEE Transactions on Antennas and Propagation, IEEE Antennas and Wireless Propagation Letters, IET Microwaves, Antennas \& Propagation, IET Electronics letter, Wireless Personal Communication (WPC), Springer, AEU-International Journal of Electronics and Communications, Microwave and optical Technology letters (MOTL), Wiley, International Journal ofAntennas and Propagation, Hindawi., Advanced Electromagnetics, Progress in Electromagnetic Research (PIER), KSII Transaction ofEngineering Science, Korea, International Journal of Microwave andWireless Technologies, Frequenz, Radio engineering etc.

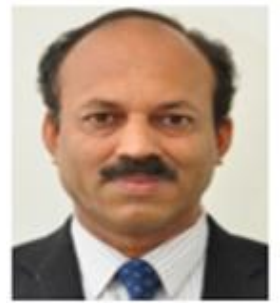

Manohara M. M. Pai is wrking as Professor in the Department of Information and Communication Technology at Manipal Institute of Technology, Manipal Academy of Higher Education, Manipal, India for the last 27 years. He holds 6 patents to his credit and has published 80 papers in National and International Journals/Conference proceedings. He is Senior Member of IEEE, Life member of ISTE and Life member of Systems Society of India. 